\title{
Survey of Mean Glandular Dose to Patients During Mammography Examinations: A Retrospective Study
}

\author{
Edem Sosu*1,2, Mary Boadu',2, Albertina Oheneba - Williams ${ }^{3}$, Eric Otu -Danquah ${ }^{3}$, \\ Annabel Ankrah ${ }^{3}$, Doreen N. Odotei ${ }^{3}$, Edwin Okoampa Boadu ${ }^{4}$, Prince Rockson ${ }^{5}$ \\ ${ }^{1}$ Radiological and Medical Sciences Research Institute, Ghana Atomic Energy Commission. Kwabenya, Accra \\ ${ }^{2}$ Graduate School of Nuclear and Allied Sciences, University of Ghana Atomic Campus, University of Ghana. Legon, Accra. \\ ${ }^{3}$ Greater Accra Regional Hospital, Accra. Ghana. \\ ${ }^{4}$ Faculty of Health and Allied Sciences, Koforidua Technical University, Koforidua, Eastern Region. \\ ${ }^{5}$ Department of Medical Imaging, School of Allied Sciences Health, \\ University of Health and Allied Sciences, Ho.
}

\begin{abstract}
Article Info
Volume 8, Issue 1

Page Number: 243-248
\end{abstract}

Publication Issue :

January-February-2021

\section{Article History}

Accepted : 23 Feb 2021

Published : 28 Feb 2021

\section{ABSTRACT}

The radiation dose delivered to patients undergoing mammography examination is of utmost importance because of the risk of cancer induction due to the process. In this work, we analyze the dose to 109 patients (214 images) who underwent mammographic examinations with a full-field digital mammography (FFDM) system. Quality control assessment was first performed using the International Atomic Energy Agency (IAEA) Human Health Series 2 and 17 protocol and the European guidelines for quality assurance in breast cancer screening and diagnosis. The results from the quality control test performed indicates that the system is functioning well. The mean glandular dose of patients analyzed shows that 23 out of 109 patients received averaged doses higher than the acceptable level at the same equivalent breast thickness of a phantom. The mammography system at the department is recommended for continuous use for imaging and screening of patients.

Keywords: Mammography, Mean Glandular Dose, Quality Control, Short Term Automatic Exposure Control

\section{INTRODUCTION}

Mammography is an important non-invasive medical imaging technique with unparalleled advantages for the detection of breast abnormalities including breast cancer [1]. It's main impact is the most common radiologic examination that directly reduces mortality from disease [2]. However, the potential risk of radiation-induced carcinogenesis is also increased with such diagnosis, thus making the assessment of breast dose very important [3]. The estimation of the absorbed dose to the breast is an important part of the quality control of the mammographic examination because there is a small but significant risk of radiation induced carcinogenesis associated with it $[4$, 5]. Knowledge of breast dose is essential for the design and performance assessment of the mammographic imaging systems. It also helps to optimise both

Copyright: (C) the author(s), publisher and licensee Technoscience Academy. This is an open-access article distributed under the terms of the Creative Commons Attribution Non-Commercial License, which permits unrestricted noncommercial use, distribution, and reproduction in any medium, provided the original work is properly cited 
equipment and technique so that the desired image quality is obtained at the lowest possible dose.

Breast dose can be estimated on the basis of measurements on patients or phantoms. Phantoms measurements are well suited to quality control and inter-system comparison. It can form the basis for dose - surveys [6, 7].

The quantity mostly used in determining the amount of radiation deposited in the breast is the Mean Glandular Dose (MDG). It is defined as the average dose to the glandular tissue of the breast and it is the most appropriate dosimetric quantity used to predict the risk of carcinogenesis [8]. Because it is difficult to measure the mean glandular dose to the breast directly and it is usual to employ conversion factors, which relate the incident air kerma to this dose. Such factors have been measured by some authors $[9,10]$ and have been calculated by others using Monte Carlo techniques. Modern mammography equipment after exposure display the mean glandular dose and this can be used for dose surveys.

\section{METHODS AND MATERIAL}

The study was performed on a "Fujifilm - Amulet $f$ " full field digital mammography equipment with Source - Image distance of $650 \mathrm{~mm}$, a target - filter combination of Tungsten - Rhodium, $\mathrm{kVp}$ range of $(23-35) \mathrm{kVp}$ and $\mathrm{mAs}$ range of $(2-600)$ at the Radiology Department of the Greater Accra Regional Hospital in Accra, Ghana. A calibrated Piranha Quality Control device connected to a laptop with 'Ocean 2014' software was used to collect data for various measurements. Patient data collected was recorded and analysed in Microsoft Excel.

Quality control test performed on the mammography system included Output repeatability \& Linearity, $\mathrm{kVp}$ Accuracy \& repeatability and Short Term Exposure control. Set-up for quality control measurement is presented in figure 1 .

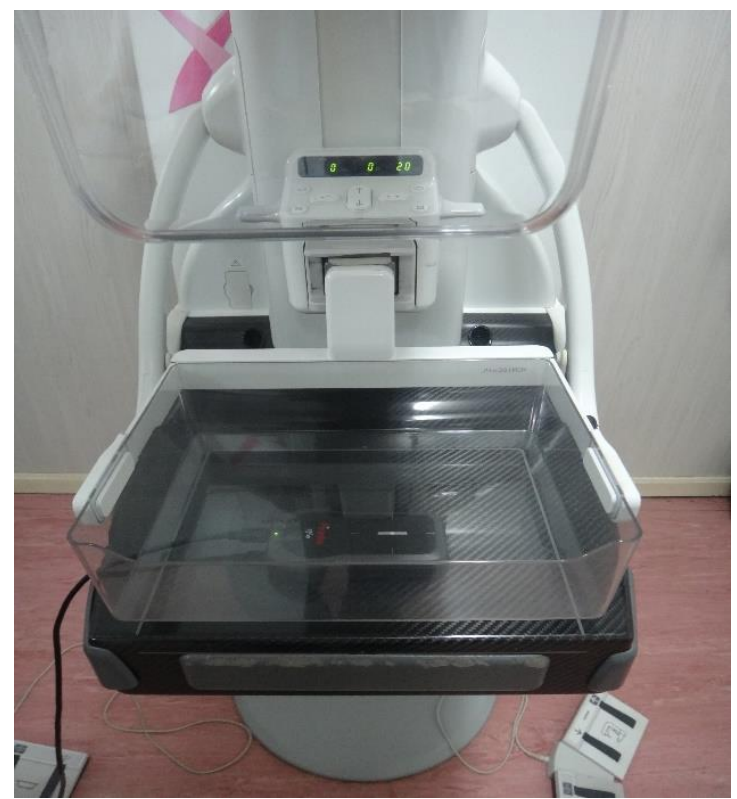

Figure 1 - Set-up for quality control measurement

The Patient's survey was done retrospectively with data from patients who had undergone a mammography examination at the department.

\section{RESULTS AND DISCUSSION}

Results from performed quality control test and were compared with International Atomic Energy Agency Human Health Series 2 and 17 [11,12] protocol and the European Quality Control of Physical and Technical Aspects of Mammography Screening respectively [13]. Results of the X-ray equipment test are presented in Table 1 . Results for $\mathrm{kVp}$ accuracy \& repeatability, Output repeatability, Output Linearity and Short term Automatic Exposure Control (AEC) are presented. Results from the $\mathrm{kVp}$ test show that the set $\mathrm{kVp}$ is accurate and repeatable. Results from the Output test shows that the repeatability of the air kerma for a given $\mathrm{mAs}$ and the linearity with the $\mathrm{mAs}$ is consistent. Results from the AEC test shows that the system has the ability to image a clinically expected breast thickness and ensures that there is adequate penetration of radiation. 
Table 1 - Results of kVp Accuracy \& repeatability, Output repeatability \& Linearity and Short term AEC

\begin{tabular}{llll}
\hline QUALITY & CONTROL & RESULTS & COMMENTS \\
TEST & & & (PASS/FAIL) \\
(Tolerance) $^{*}$ & & &
\end{tabular}

\begin{tabular}{llll}
\hline $\mathrm{kVp}$ accuracy & $( \pm 5 \%)$ & $0.50 \%$ & Pass \\
$\mathrm{kVp}$ & Difference & $0.39 \%$ & Pass \\
repeatability & $\leq 5 \%$ & & \\
at $28 \%$ & $(\mathrm{COV} \leq 5 \%)$ & $0.21 \%$ & Pass \\
Output & Difference & $0.07 \%$ & Pass \\
repeatability & $\leq 5 \%$ & & \\
& $(\mathrm{COV} \leq 5 \%)$ & $0.07 \%$ & Pass \\
Output & Max L1 $(<$ & $-0.06 \%$ & Pass \\
linearity & $\pm 10 \%)$ & & \\
& Max L2 $(<$ & $-0.23 \%$ & Pass \\
& $\pm 10 \%)$ & & \\
Short term & Automatic & 2.76 & Pass \\
Exposure Control $(\leq 5 \%)$ & & \\
\hline$* 14]$ & & &
\end{tabular}

\section{Patient survey}

Data from 109 patients (214 images) who underwent mammographic examinations with a full-field digital mammography (FFDM) system between January 2017 and April 2018 were analysed. 107 patients underwent imaging of both breasts i.e two views for each breast whiles 2 patients underwent imaging of one breast. The average dose received by the left and right breast was $3.83 \mathrm{mGy}$ and $3.62 \mathrm{mGy}$ respectively. The maximum and minimum dose recorded were $12.67 \mathrm{mGy}$ and $1.67 \mathrm{mGy}$ for the left breast and 10.08 $\mathrm{mGy}$ and $1.65 \mathrm{mGy}$ for the right breast. Mean of total dose received by both breast was $3.65 \mathrm{mGy}$ with a range of $(1.69-10.18) \mathrm{mGy}$. Average $\mathrm{kVp}$ for all data analysed was $28.41 \mathrm{kVp}$ with a minimum and maximum values of $26 \mathrm{kVp}$ and $30.5 \mathrm{kVp}$.

\section{Age distribution of patients}

The ages of the patients are presented in figure 2. It shows that the age group of 51 - 55 years recorded the highest frequency representing $\sim 34 \%$ of cases surveyed whiles the age group of $66-70$ years recorded the lowest number of patients representing $2.75 \%$ of reported cases. No cases were recorded for patients below 30 years and above 71 years. No males were recorded in this study.

\section{Breast thickness and $\mathrm{kVp}$ assessment}

A graph of average compressed breast thickness plotted against average $\mathrm{kVp}$ showed that as the thickness of the compressed breast increased, the voltage required to give the desired image also increased. This is presented in figure 3 . This conforms well to literature.

Mean glandular dose (MGD) Simulated Patient vrs Recorded Patient measurement

From the compressed breast thickness and mean glandular dose recorded, the total dose received by the patient was computed.

The breast was then simulated using the average breast thickness of the patient. The mean glandular dose corresponding to the simulated patient thickness was then computed. A graph to compare of average dose received by the patient (Avg-D) and Acceptable dose (ACC) at an average thickness of the breast was plotted (figure )4. The mean glandular dose of patients analysed showed that 23 patients representing approximately $21 \%$ of 109 patients received averaged doses higher than the acceptable level at the same equivalent breast thickness. 
Edem Sosu et al Int J Sci Res Sci \& Technol. January-February-2021; 8 (1) : 243-248

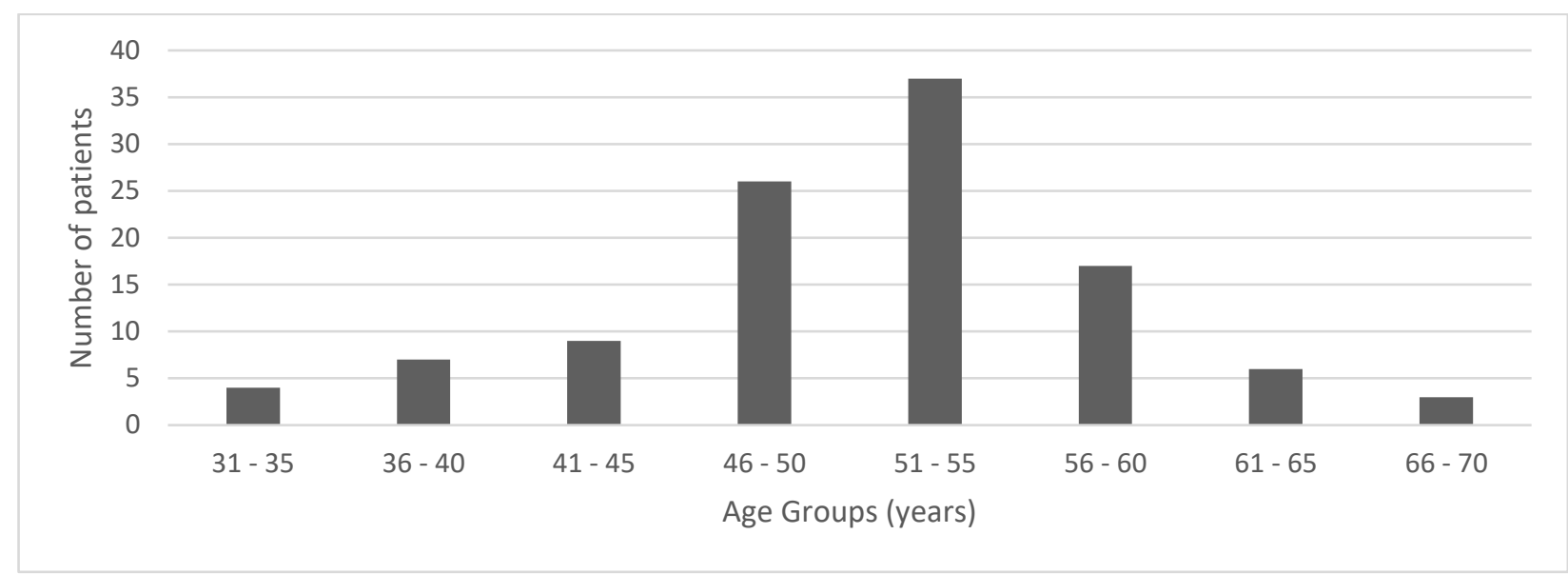

Figure 2 - Age distribution of patients

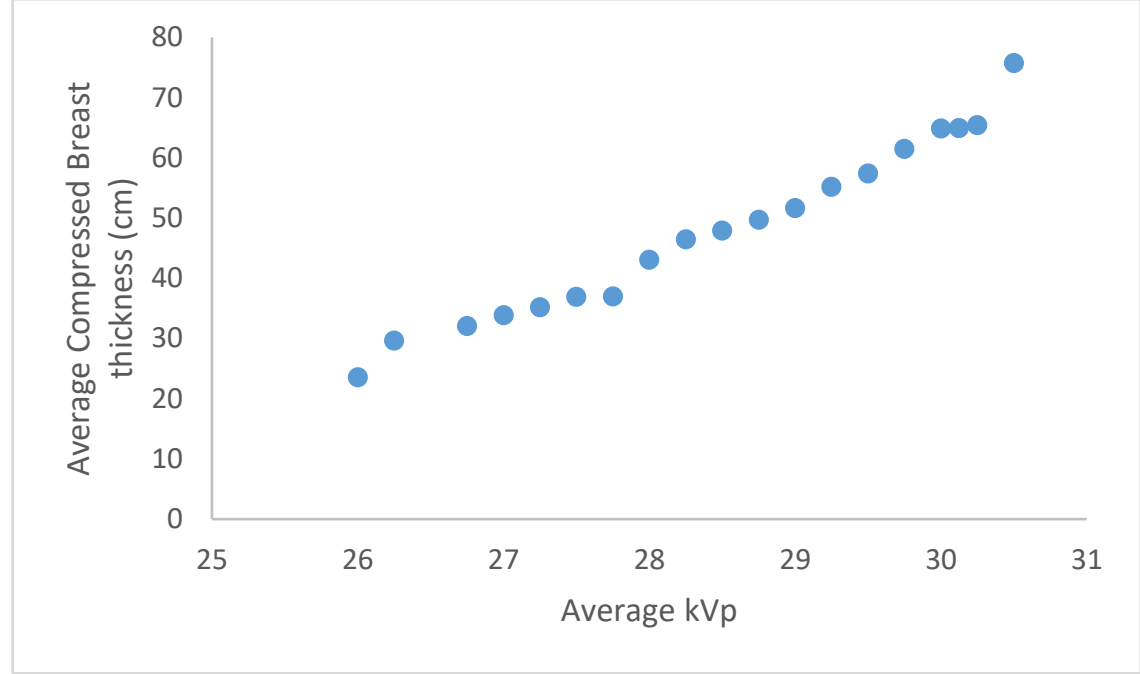

Figure 3: A graph of average compressed breast thickness with $\mathrm{kVp}$

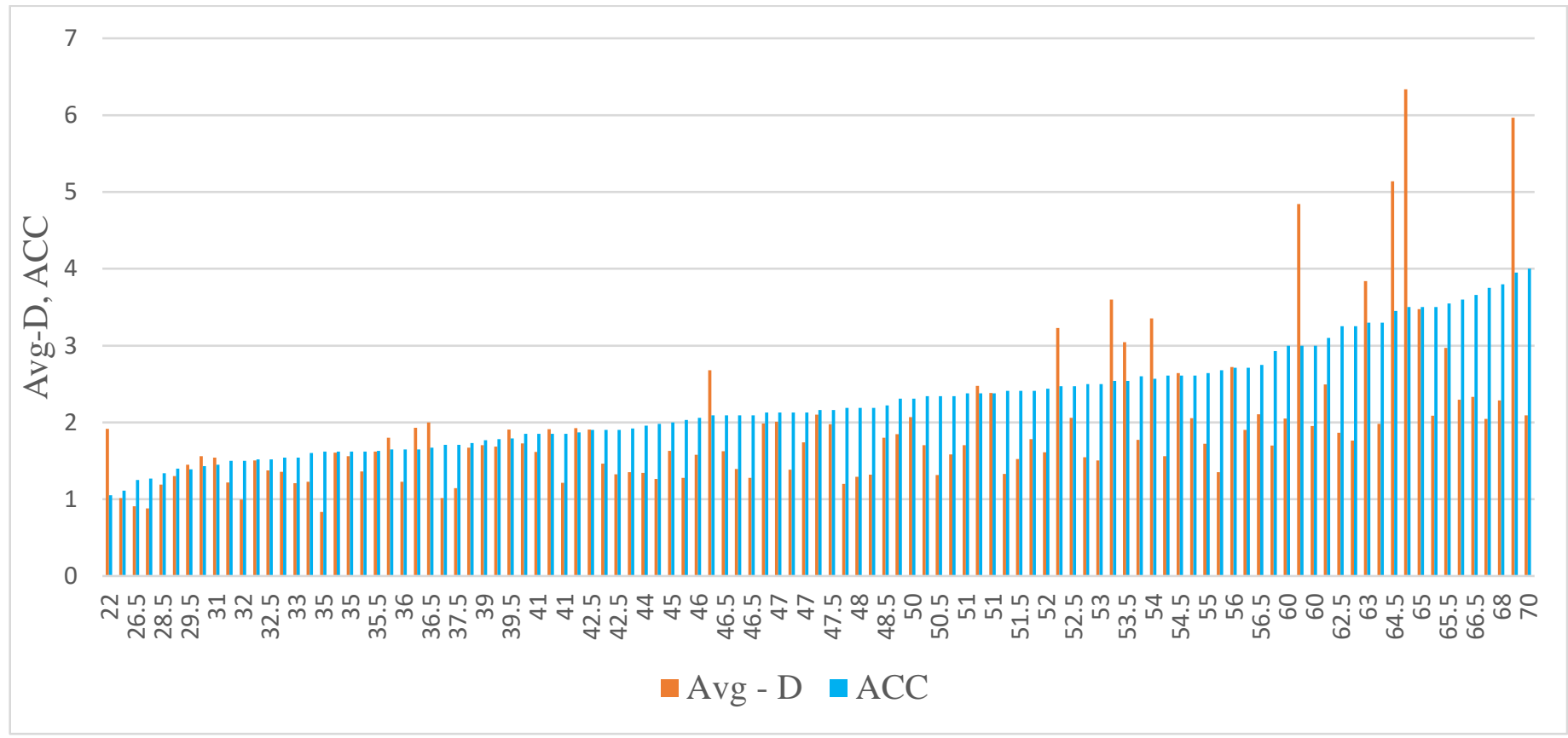

Figure 4: Comparism of average dose received by patient (Avg-D) and Acceptable dose (ACC) at average thickness of breast 


\section{CONCLUSION}

Mean Glandular Dose (MGD) values for typical breast, simulated by the homogenous PMMA have been estimated. The PMMA slabs from $2.0 \mathrm{~cm}$ to $7.0 \mathrm{~cm}$ thick are equivalent to the typical breast from $2.1 \mathrm{~cm}$ to $9.0 \mathrm{~cm}$ thick. The percentage difference between the estimated (calculated) dose and the console (patient) displayed dose was within the acceptable level of $50 \%$ as it is shown in Table 7. The doses displayed with the exception of the $9.00 \mathrm{~cm}$ phantom compares well with international limits. Quality control and image quality analysis performed on the system indicates that the Fujifilm - Amuletf full field digital mammography $\mathrm{x}$-ray equipment at the Greater Accra Regional Hospital, Accra - Ghana is functioning under optimized conditions. It is therefore recommended for further diagnosis.A conclusion might elaborate on the importance of the work or suggest applications and extensions. Authors are strongly encouraged not to call out multiple figures or tables in the conclusion-these should be referenced in the body of the paper.

\section{ACKNOWLEDGEMENT}

The author wishes to acknowledge the support of the International Atomic Energy Agency, Ghana Atomic Energy Commission, Head and staff of the Greater Accra Regional Hospital, Accra - Ghana

\section{REFERENCES}

[1]. International Atomic Energy Commission (IAEA). Optimization of the radiological protection of patients: Image quality and dose in mammography (coordinated research in Europe). IAEA-TEC DOC-1447. May 2005. Page 4

[2]. Sosu, E. K., et al., Determination of dose delivery accuracy and image quality in full - Field digital mammography, Journal of Radiation Research and
Applied

Sciences

(2018),

https://doi.org/10.1016/j.jrras.2018.02.002

[3]. Donga, L., Chua, T. C., Lee, J. S., Lanc, G. Y., Wua, T. H., Yeh, Y. H., et al. (2002). Estimation of mean-glandular dose from monitoring breast entrances air kerma using a high sensitivity metal oxide semiconductor field effect transistor (MOSFET) dosimeter system in mammography. Applied Radiation and Isotopes, 57(2002), 791799

[4]. Dance, D. R., Monte Carlo calculation of conversion factors for the estimation of mean glandular breast dose. Physics in Medicine and Biology. 1990 Number 35, Pages 1211 - 1219

[5]. ICRP (International Commission on Radiological Protection). Recommendations of the International Commission on Radiological Protection. ICRP Publication 60, Annals of the ICRP, 1991. Volume 21, Pages $1-3$.

[6]. IPSM (Institute of Physical Sciences in Medicine) 1994. The commissioning and routine testing of mammographic $X$ - ray systems. IPSM report 59, 2nd Edition. IPSM, York. Pages 11 - 12

[7]. Hogg Peter, Kelly Judith, Mercer Claire. Digital Mammography: A Holistic Approach. Radiation Dose in Mammography. 2015, Pages 153 - 161. DOI: 10.1007/978-3-319-04831-418.

[8]. Hammerstein G R, Miller D W, White D R, Masterson M E, Woodard H Q and Laughlin J S (1979). Absorbed radiation dose in mammography. Radiology Number 130, Pages $485-91$

[9]. Stanton L, Villafana T,Day J L and Lightfoot, D A (1984) Dosage evaluation in mammography Radiology. Number 150. Pages 577-84

[10]. Rosenstein M, Andersen L W and Warner G G. (1985). Handbook of Glandular Tissue Doses in Mammography FDA 85-8239 (Rockville, MD: US Department of Health and Human Services)

[11]. IAEA. (2009). Quality Assurance Program For Screen Film Mammography. IAEA Human Health Series No. 2. Pg 125-130/203-205 
[12]. IAEA. (2011). Quality Assurance Program for Digital Mammography. IAEA Human Health Series No. 17. Pg 109-114

[13]. EC (2006). European guidelines for quality assurance in breast cancer screening and diagnosis (fourth edn.) European Commission, Luxembourg, Office for Official Publications of the European Communities

[14]. Elmore, J. G., Miglioretti, D. L., \& Carney, P. A. (2003). Does practice make perfect when interpreting mammography? Part II. J Natl Cancer Inst, 95, $250-252$.

\section{Cite this article as :}

Edem Sosu, Mary Boadu,Albertina Oheneba Williams, Eric Otu - Danquah, Annabel Ankrah, Doreen N. Odotei, Edwin Okoampa Boadu, Prince Rockson, " Survey of Mean Glandular Dose to Patients During Mammography Examinations: A Retrospective Study", International Journal of Scientific Research in Science and Technology(IJSRST), Print ISSN : 2395-6011, Online ISSN : 2395-602X,Volume 8, Issue 1, pp.243-248, January-February-2021. Available at doi : https://doi.org/10.32628/IJSRST218144

Journal URL : https://ijsrst.com/IJSRST218144 